Article

\title{
Dry Reforming of Methane Using a Nickel Membrane Reactor
}

\author{
Jonas M. Leimert ${ }^{*, \dagger}$ (D), Jürgen Karl ${ }^{\dagger, \ddagger}$ and Marius Dillig ${ }^{\dagger, \ddagger}$ \\ FAU Erlangen-Nuremberg; Chair of Energy Process Engineering, Fuerther Str. 244f, \\ 90429 Nuremberg, Germany; juergen.karl@fau.de (J.K.); marius.dillig@fau.de (M.D.) \\ * Correspondence: jonas.leimert@fau.de; Tel.: +49-911-5302-9029 \\ + Current address: FAU Erlangen-Nuremberg; Chair of Energy Process Engineering, Fuerther Str. 244f, \\ 90429 Nuremberg, Germany. \\ $\ddagger$ These authors contributed equally to this work.
}

Received: 27 October 2017; Accepted: 8 December 2017; Published: 12 December 2017

\begin{abstract}
Dry reforming is a very interesting process for synthesis gas generation from $\mathrm{CH}_{4}$ and $\mathrm{CO}_{2}$ but suffers from low hydrogen yields due to the reverse water-gas shift reaction (WGS). For this reason, membranes are often used for hydrogen separation, which in turn leads to coke formation at the process temperatures suitable for the membranes. To avoid these problems, this work shows the possibility of using nickel self-supported membranes for hydrogen separation at a temperature of $800{ }^{\circ} \mathrm{C}$. The higher temperature effectively suppresses coke formation. The paper features the analysis of the dry reforming reaction in a nickel membrane reactor without additional catalyst. The measurement campaign targeted coke formation and conversion of the methane feedstock. The nickel approximately 50\% without hydrogen separation. The hydrogen removal led to an increase in methane conversion to $60-90 \%$.
\end{abstract}

Keywords: membranes; hydrogen; dry reforming; nickel; membrane reactor

\section{Introduction}

The methane dry reforming (MDR) process

$$
\begin{array}{r}
\mathrm{CH}_{4}+\mathrm{CO}_{2} \rightleftharpoons 2 \mathrm{CO}+2 \mathrm{H}_{2} \\
\Delta H_{298}^{0}=247.8 \mathrm{~kJ} \mathrm{~mol}^{-1}
\end{array}
$$

utilizes two climate-damaging gases to form synthesis gas as an alternative to the widely used steam reforming process [1,2]. It has attracted attention recently due to the shale gas findings in the United States and the possibility of using $\mathrm{CO}_{2}$ as a feedstock, which could be utilized from future carbon capture and sequestration (CCS) activities in fossil fuel power plants. The $\mathrm{H}_{2} / \mathrm{CO}$ ratio of the product gas in the range of $1-2.5$ is also much more favorable for syntheses such as methanol [3,4].

Drawbacks of this process are coking of catalysts, a higher endothermicity in comparison with steam reforming and a low hydrogen yield due to the progress of the reverse water-gas shift reaction (WGS). Reverse WGS yields high amounts of water, especially at higher process pressures, which cannot be used in subsequent process steps [5]. To enhance the reaction, membrane reactors with hydrogen permeable membranes are extensively discussed in recent literature [1-3,6].

The interest and activities for the realization of this process with a membrane reactor has been mostly academical: Bosko et al. [7] used a membrane reactor with Pd based membranes with a Rh catalyst at temperatures of up to $500{ }^{\circ} \mathrm{C}$. They found an equilibrium shift, which raised methane conversion and hydrogen recovery. Galucci et al. [1] compared dry reforming in a conventional reactor and a membrane reactor with porous and dense Pd membranes. As expected, the dense membrane 
showed higher selectivity and coke formation was lower than without the membranes. Paturzo et al. used a Ru-based catalytic membrane reactor and achieved a higher conversion of the feedstock due to the hydrogen separation [6].

Membrane reactors combine separation and synthesis steps, normally with benefits in terms of selectivity, yield or conversion towards the desired product due to the separation or addition of a reactant with the membrane. Integration of synthesis and separation makes processes more compact and downstream cleaning of the product obsolete [8].

Hydrogen production with membrane reactor follows the approach to separate the hydrogen product stream directly from the reactor. The first approach to this concept was given by Pfefferle in 1966 to increase process yields and conversion [9]. Because of the enhanced conversion induced by Le Chatelier's principle, the conversion of the products might be higher than the thermodynamic equilibrium without membrane separation known as the equilibrium shift effect [10].

\section{Materials and Methods}

Several steps characterize the permeation of a diatomic gas through a dense body: hydrogen adsorption on the surface, dissociation into protons and dissolution into the metal, sometimes referred to as hydrogen solution. The rate-controlling step of the process is in most cases hydrogen diffusion through the metal as protons. The protons finally recombine and desorb as molecular hydrogen from the solid [11].

The following equation describes the hydrogen molar flow through a dense membrane $\dot{n}_{\mathrm{H}_{2}}$, which depends on the permeability $P$ of the membrane material, membrane area $A$, thickness $\Delta x$ and the square root of the pressure difference between retentate and permeate $p_{1}, p_{2}$ respectively [12].

$$
\dot{n}_{\mathrm{H}_{2}}=\frac{-P A}{\Delta x}\left(p_{1}{ }^{n}-p_{2}{ }^{n}\right)
$$

In addition, some figures for hydrogen yield and hydrocarbon conversion have to be established to characterize the impact of membrane separation on the synthesis gas. The maximum amount of hydrogen $\dot{n}_{\mathrm{H}_{2}, \max }$ that is possible to generate from the methane feed $\dot{n}_{\mathrm{CH}_{4}, \text { feed }}$ can be calculated according to the reaction equations of the dry reforming and the water-gas shift reaction:

$$
\dot{n}_{\mathrm{H}_{2}, \max }=4 \dot{n}_{\mathrm{CH}_{4}}+\dot{n}_{\mathrm{H}_{2}}+\dot{n}_{\mathrm{CO}}
$$

The molar flow rates indicate the flow rate of the specific gas in the synthesis gas without membrane separation. To describe the hydrogen separation in relation to the amount of treated gas, the measured hydrogen permeate flow $\dot{n}_{\mathrm{H}_{2}, \mathrm{M}}$ and the complete hydrogen flow in permeate and retentate $n_{\mathrm{H}_{2}}$ is divided by this value resulting in the hydrogen recovery for the membrane $R_{\mathrm{H}_{2}}$ and the hydrogen yield for whole reaction system $Y_{\mathrm{H}_{2}}$, respectively:

$$
\begin{gathered}
R_{\mathrm{H}_{2}}=\frac{\dot{n}_{\mathrm{H}_{2}, M}}{\dot{n}_{\mathrm{H}_{2}, \text { max }}} \\
Y_{\mathrm{H}_{2}}=\frac{\dot{n}_{\mathrm{H}_{2}}}{\dot{n}_{\mathrm{H}_{2}, \max }}
\end{gathered}
$$

The feedstock in the dry reforming reaction consists of $\mathrm{CO}_{2}$ and $\mathrm{CH}_{4}$. To describe the course of the reaction, the $\mathrm{CH}_{4}$ conversion $\mathrm{X}$ is introduced:

$$
\mathrm{X}_{\mathrm{CH}_{4}}=1-\frac{\dot{n}_{\mathrm{CH}_{4}, \text { ret }}}{\dot{n}_{\mathrm{CH}_{4}, \text { feed }}}
$$

The balance can also be given on energetic basis forming with the specific energy content of retentate $E_{r e t}$ and permeate $E_{p e r}$ : 


$$
\begin{gathered}
E_{\text {ret }}=\frac{\dot{n}_{\mathrm{CH}_{4}, \text { ret }} H_{l, \mathrm{CH}}+\dot{n}_{\mathrm{CO}, \text { ret }} H_{l, \mathrm{CO}}+\dot{n}_{\mathrm{H}_{2}, \text { ret }} H_{l, \mathrm{H}_{2}}}{\dot{n}_{\mathrm{CH}_{4}, \text { feed }} H_{l, \mathrm{CH}_{4}}} \\
E_{\text {per }}=\frac{\dot{n}_{\mathrm{H}_{2}, \text { per }} H_{l, \mathrm{H}_{2}}}{\dot{n}_{\mathrm{CH}_{4}, \text { feed }} H_{l, \mathrm{CH}_{4}}}
\end{gathered}
$$

To give an impression on the heating requirements, the specific heat duty $H D_{\text {spec }}$ is introduced also considering the combustor efficiency $\eta_{c o m b}$. It is calculated under the assumption that the methane feed is only converted by MDR:

$$
H D_{\text {spec }}=\frac{1}{\eta_{\text {comb }}} \cdot \frac{\left(\dot{n}_{\mathrm{CH}_{4}, \text { feed }}-\dot{n}_{\mathrm{CH}_{4}, \text { ret }}\right) \Delta H_{298}^{0}}{\dot{n}_{\mathrm{CH}_{4}, \text { feed }} \mathrm{H}_{l, \mathrm{CH}_{4}}}
$$

\section{Experimental}

For the experiments, the test rig as described in the previous publication in [13] was used with some changes, as shown in Figure 1. Instead of the previous tube furnace, a larger furnace with a length of $500 \mathrm{~mm}$ was used to achieve an increased heated membrane area. As the volumetric flow rate through the membrane bundle was much higher than in the previous experiments, a thermal mass flow meter was used for the measurement of the hydrogen flow.

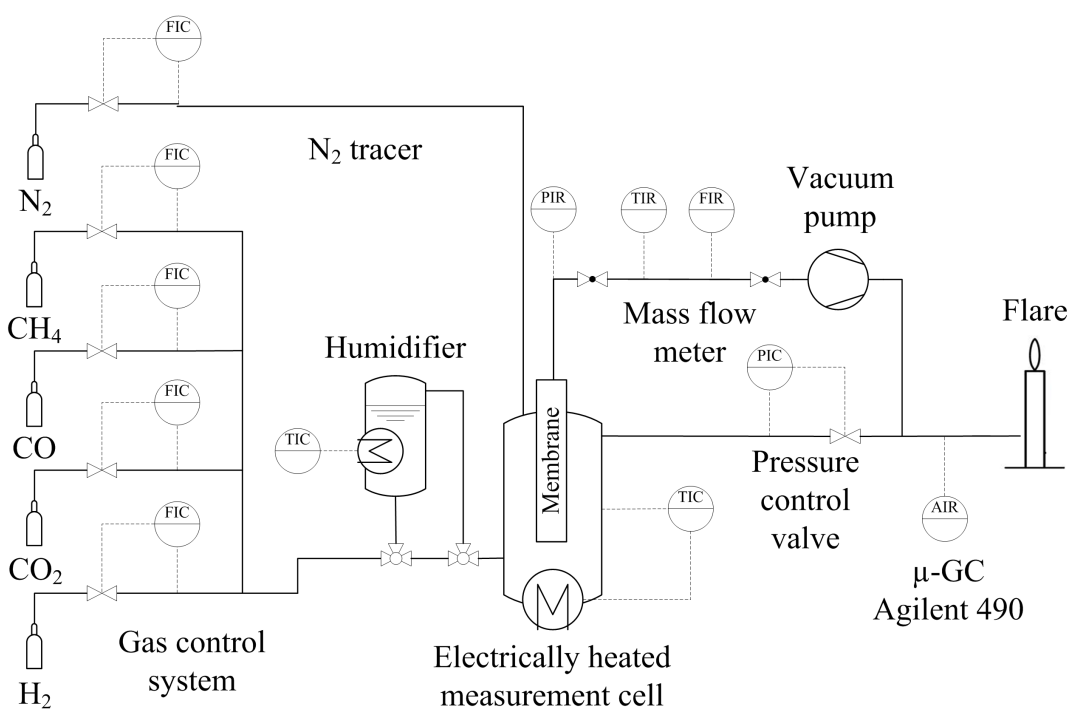

Figure 1. Piping and instrumentation diagram of the membrane test rig for membrane bundle experiments.

To determine the influence of the hydrogen separation on gas composition the hydrogen permeate flow was united with the remaining retentate flow after the measurement cell and sub-sequentially analyzed using a $\mu$-GC "Agilent 490 " for the components $\mathrm{CO}, \mathrm{CO}_{2}, \mathrm{~N}_{2}$ and $\mathrm{CH}_{4}$. This procedure was chosen to measure all components in one device and stay within a well-calibrated and reliable concentration range of the measurement system. The synthesis gas was measured discontinuously with one sample every five minutes. Each operation point was measured at least five times and checked for steady state concentrations.

The impermeability of the membrane system to gases other than hydrogen was proved by tests in gas mixtures without hydrogen, where the inner pressure of the membrane remained constant. Although direct measurement of $\mathrm{H}_{2}$ is not possible because helium is used as carrier gas in the $\mu$-GC system, it can be calculated as the difference to $100 \%$. Water vapor was condensed prior to the GC measurement, so this difference accounts only for the hydrogen content of the gas. 
An additional mass flow controller supplied nitrogen as a tracer component to measure the dry volumetric flow of the different mixtures. It was added to the top end of the measurement cell to prevent contact with the membrane bundle for a higher hydrogen partial pressure. It also acts as a gas barrier between membrane sealing and measurement cell to prevent condensation at the air-cooled sealing material.

For an effective separation process, a high surface area and therefore a high number of single membranes is needed. To avoid complicated sealing constructions at the desired process temperature, the sealing is placed outside the measurement cell, where the temperature is below $50{ }^{\circ} \mathrm{C}$. Preliminary tests showed good results for epoxy resins, which are also used for membrane sealing in water purification [14], in terms of leak rate and durability.

The developed membrane bundle with 52 single capillaries as shown by Figure 2 had a leak rate ranging from $1 \times 10^{-5}$ to $10 \times 10^{-5} \mathrm{mbar}^{1 \mathrm{~s}^{-1}}$, which allowed molar flows only well below the prospected hydrogen flow through the membrane and therefore a high purity of the generated hydrogen. With this sealing, an unlimited up-scaling is possible in principle: the number of membranes is limited only by reactor geometry. The capillaries are made from Ni201 (Material No. 2.4068) with a diameter of $2 \mathrm{~mm}$ and a wall thickness of $0.1 \mathrm{~mm}$, supplied by Shaanxi Taipu Rare Metal Materials Ltd., Co. (Baoji, China). The length is $750 \mathrm{~mm}$ with a heated length of approximately $400 \mathrm{~mm}$ due to the limitations of the tube furnace. The membrane bundle therefore has a membrane area of $0.13 \mathrm{~m}^{2}$.

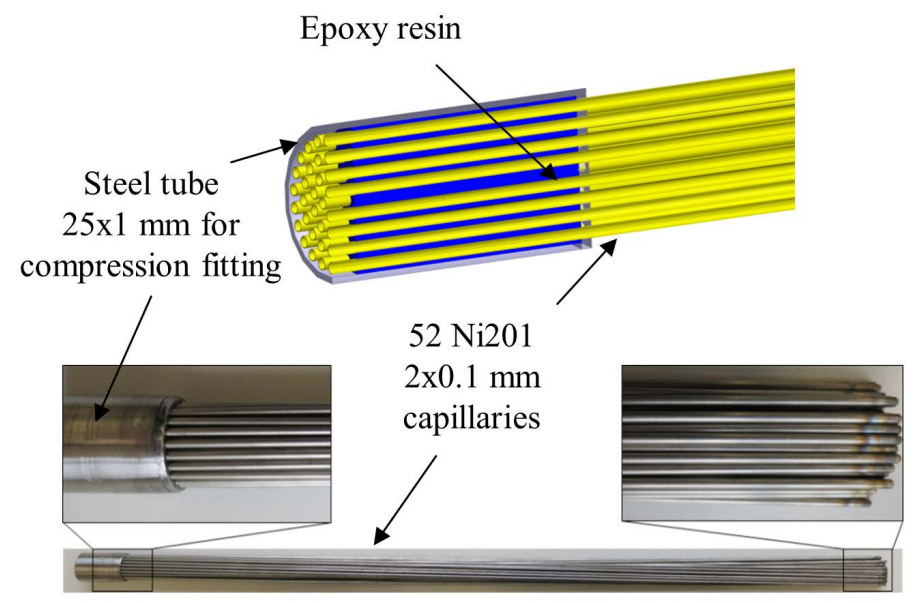

Figure 2. Membrane bundle with CAD (Computer aided design) sketch of the developed epoxy resin membrane sealing.

Table 1 shows the parameters of the measurement campaign. In summary, the three parameters system pressure, $\mathrm{CO}_{2} / \mathrm{CH}_{4}$ ratio and flow rate were studied. These parameters were varied by adjusting the flow rates of the different species. Pressure increase also had an influence on the residence time of the mixture in the membrane reactor. The increase of $\mathrm{CO}_{2} / \mathrm{CH}_{4}$ should result in a higher $\mathrm{CH}_{4}$ conversion. The adjustment of the flow rate should change the contact time of the reactants with the membranes while keeping the other parameters constant. The Reynolds number of the gas mixture entering the measurement cell has a Reynolds number of 20 indicating a laminar flow.

When one of the main parameters was changed, the other three remained constant. Target values of the experimental campaign were the hydrogen recovery and methane conversion. One reference case was kept constant in all variations, which is identified in the table as "Ref.". 
Table 1. Experimental settings for dry reforming parameter study, volumetric flow rates given at standard temperature and pressure $p_{0}=1.013 \mathrm{bar}, T_{0}=273 \mathrm{~K}$.

\begin{tabular}{|c|c|c|c|c|c|c|c|}
\hline Variation & OP & $\begin{array}{c}\mathrm{CO}_{2} \text { Flow } \\
\left(\mathrm{mL} \min ^{-1}\right)\end{array}$ & $\begin{array}{c}\mathrm{CH}_{4} \text { Flow } \\
\left(\mathrm{mL} \text { min }^{-1}\right)\end{array}$ & $\begin{array}{c}\text { Flow Rate } \\
\left(\mathrm{mL} \min ^{-1}\right)\end{array}$ & $\begin{array}{l}\text { Pressure } \\
\quad \text { (bar) }\end{array}$ & $\begin{array}{c}\mathrm{CO}_{2} / \mathrm{CH}_{4} \text { Ratio } \\
(-)\end{array}$ & $\begin{array}{c}\text { Contact Time } \\
(\mathrm{s})\end{array}$ \\
\hline \multirow{4}{*}{ Pressure } & $\mathrm{P} 1$ & 150 & 150 & 300 & 1.0 & 1.0 & 10.6 \\
\hline & P2 & 150 & 150 & 300 & 2.0 & 1.0 & 21.1 \\
\hline & P3 & 150 & 150 & 300 & 3.0 & 1.0 & 31.7 \\
\hline & Ref. & 150 & 150 & 300 & 4.0 & 1.0 & 42.3 \\
\hline \multirow{4}{*}{$\mathrm{CO}_{2} / \mathrm{CH}_{4}$ ratio } & Ref. & 150 & 150 & 300 & 4.0 & 1.0 & 42.3 \\
\hline & $\mathrm{C} 1$ & 180 & 120 & 300 & 4.0 & 1.5 & 42.3 \\
\hline & $\mathrm{C} 2$ & 200 & 100 & 300 & 4.0 & 2.0 & 42.3 \\
\hline & $\mathrm{C} 3$ & 225 & 75 & 300 & 4.0 & 3.0 & 42.3 \\
\hline \multirow{4}{*}{ Flow rate } & F1 & 100 & 100 & 200 & 4.0 & 1.0 & 63.4 \\
\hline & Ref. & 150 & 150 & 300 & 4.0 & 1.0 & 42.3 \\
\hline & F2 & 225 & 225 & 450 & 4.0 & 1.0 & 28.2 \\
\hline & F3 & 300 & 300 & 600 & 4.0 & 1.0 & 21.1 \\
\hline
\end{tabular}

\section{Results and Discussion}

The nickel membranes from this work also show an interesting alternative to the commonly used Pd membranes as their operation temperature is higher, which reduces coke deposition. Membrane systems operated at lower temperature show carbon formation even leading to membrane destruction $[15,16]$. The nickel membranes also showed catalytic properties in the first experiments, which could reduce the amount of catalyst needed in the process. Considering the previously addressed problems for the dry reforming process, such as coke formation and reverse water gas shift, the goals of this campaign were:

- Analysis of coke formation during dry reforming reaction

- Determination of catalytic activity of the membrane surface and $\mathrm{CH}_{4}$ conversion

- Measurement of hydrogen yield and recovery

\subsection{Analysis of Coke Formation on Membranes}

During a preliminary campaign, coke formation on the membrane bundle was detected and investigated. Figure 3 shows the operation point of the feed of this experiment in a ternary diagram of the elements carbon, hydrogen and oxygen. Due to the stoichiometric ratio of $\mathrm{CH}_{4}$ and $\mathrm{CO}_{2}$, it was located at the intersection of the connecting lines between $\mathrm{CH}_{4} / \mathrm{CO}_{2}$ and $\mathrm{H}_{2} / \mathrm{CO}$. The connecting lines between two pure substances give the mixtures between these components depending ob the mixing ratio.

The three solid lines give the thermodynamic boundaries of graphitic carbon formation calculated with FactSage. With these boundaries, the formation of carbon is thermodynamically possible and limited by formation kinetics. Therefore, at the process temperature of $800{ }^{\circ} \mathrm{C}$, coke deposition was possible with this gas sample. When hydrogen is removed by the membranes, the point of the mixture moves straight away from the point of pure hydrogen and stays in the coke formation region.

During the campaign, a rise in pressure difference before and after the measurement cell was detected alongside with a leakage of the membrane bundle. After demounting, both effects could be traced back to coke formation on the top end of the membrane bundle, as shown in Figure 4. The part of the membrane that was operated at process temperature of $800{ }^{\circ} \mathrm{C}$ showed no coke formation, while at the upper part outside the tube furnace a ring-like coke formation was found. The membrane had at this point a much lower temperature of approximately $800-400{ }^{\circ} \mathrm{C}$, which was sufficient for carbon deposits. At the colder parts of the membrane more than $50 \mathrm{~mm}$ above furnace top end, no coke formation was detected probably due to lower kinetics caused by the cold membrane surface. The leakage was caused by one capillary tube, which had a hairline crack detected with an optical microscope; it was removed and close-welded. 


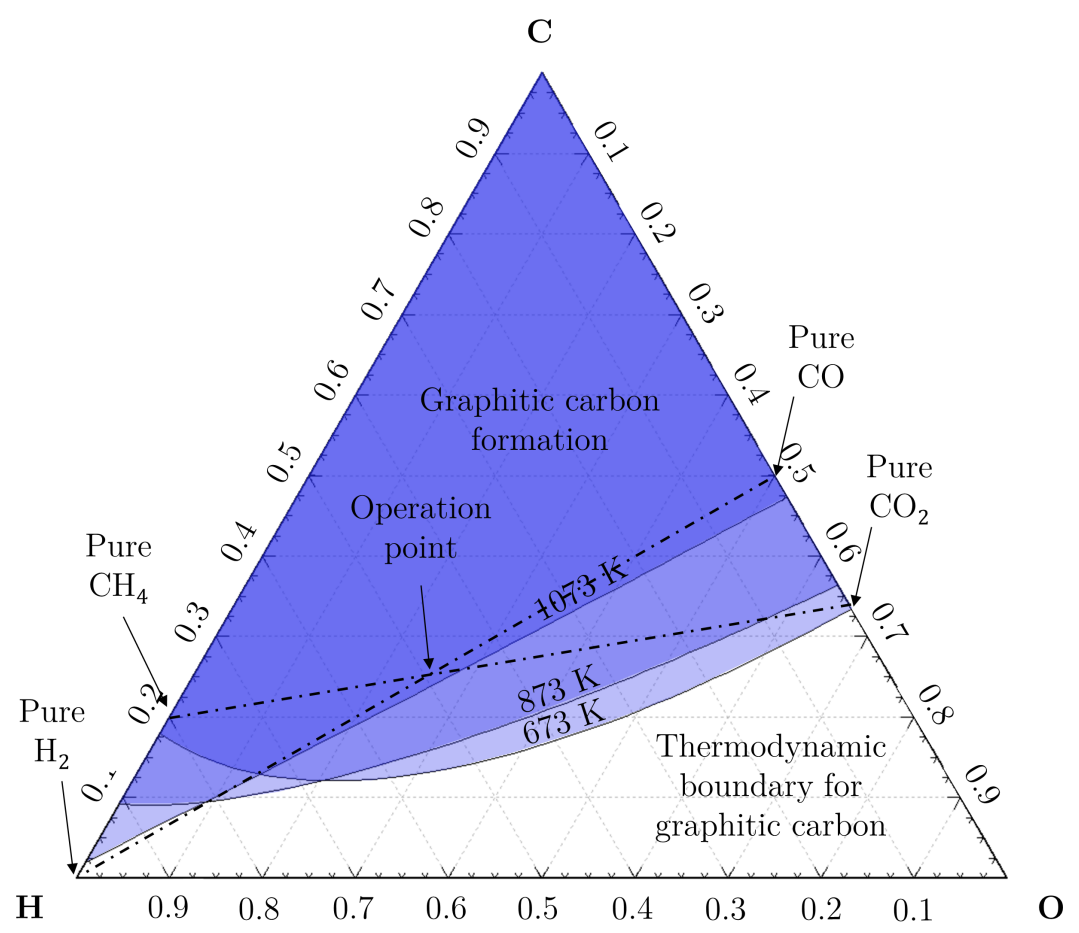

Figure 3. Ternary diagram for characterization of coke formation tendency in dry reforming experiment at a $\mathrm{CH}_{4} / \mathrm{CO}_{2}$ ratio of 1:1, graphitic carbon boundaries calculated using FactSage.

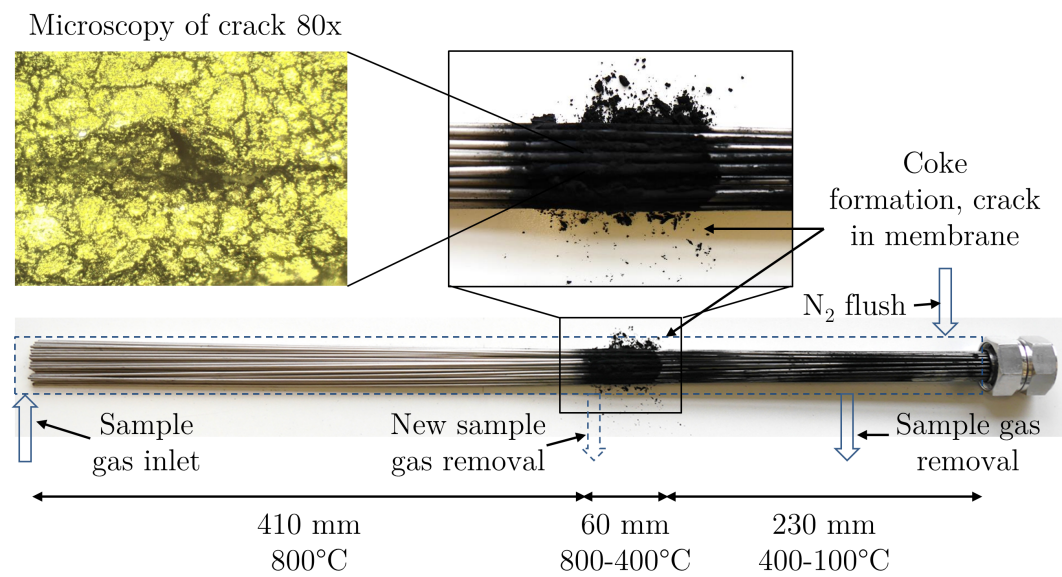

Figure 4. Photography of coke formation on membrane bundle and microscopy of membrane crack after usage in dry reforming reaction at a $\mathrm{CH}_{4} / \mathrm{CO}_{2}$ ratio of $1: 1$; operation temperature: $800{ }^{\circ} \mathrm{C}$.

To avoid coke formation on membranes, only gas compositions at process temperatures should be used which have no tendency to coke. As outlined above, temperatures lower than the operating temperature of the membrane also have to be considered when the whole membrane surface comes into contact with the gas. As a countermeasure to coking, it is also possible to sweep the colder parts of the membrane with an inert gas such as nitrogen. This measure was also taken with the shown membrane bundle: After the shown campaign, the gas outlet was moved to a lower position, where high membrane temperatures are guaranteed. The nitrogen tracer was used to flush the colder parts of the membrane and prevent coke formation. 


\subsection{Membrane Reactor Performance}

Figure 5 illustrates the process with the reference point at a $\mathrm{CO}_{2} / \mathrm{CH}_{4}$ ratio of 1.0 and a system pressure of 4.0 bar. The abscissa shows the hydrogen recovery by the nickel membranes, as introduced in Section 2: At a hydrogen recovery of zero, no hydrogen is separated by the membranes. The fact that at this condition already significant amounts of $\mathrm{CO}$ are measured shows the catalytic activity of the membrane surface even without hydrogen separation.

It also shows in this case more $\mathrm{CO}_{2}$ than $\mathrm{CH}_{4}$ is consumed resulting in a higher $\mathrm{CO}$ content as a result from reverse water gas shift reaction. When the permeate pressure is lowered and hydrogen is separated to a hydrogen recovery of up to 0.5 , hydrogen recovery and methane conversion can be increased from initial $50 \%$ to nearly $60 \%$. The results also show that the $\mathrm{H}_{2} / \mathrm{CO}$ ratio of the product gas can be adjusted by hydrogen separation. This might be an interesting effect for synthesis gas conditioning. It is important to note that these measurements show the overall gas composition after mixing the permeate back to the retentate. This procedure was chosen to measure all components in one device and stay within a well-calibrated and reliable concentration range of the measurement system.
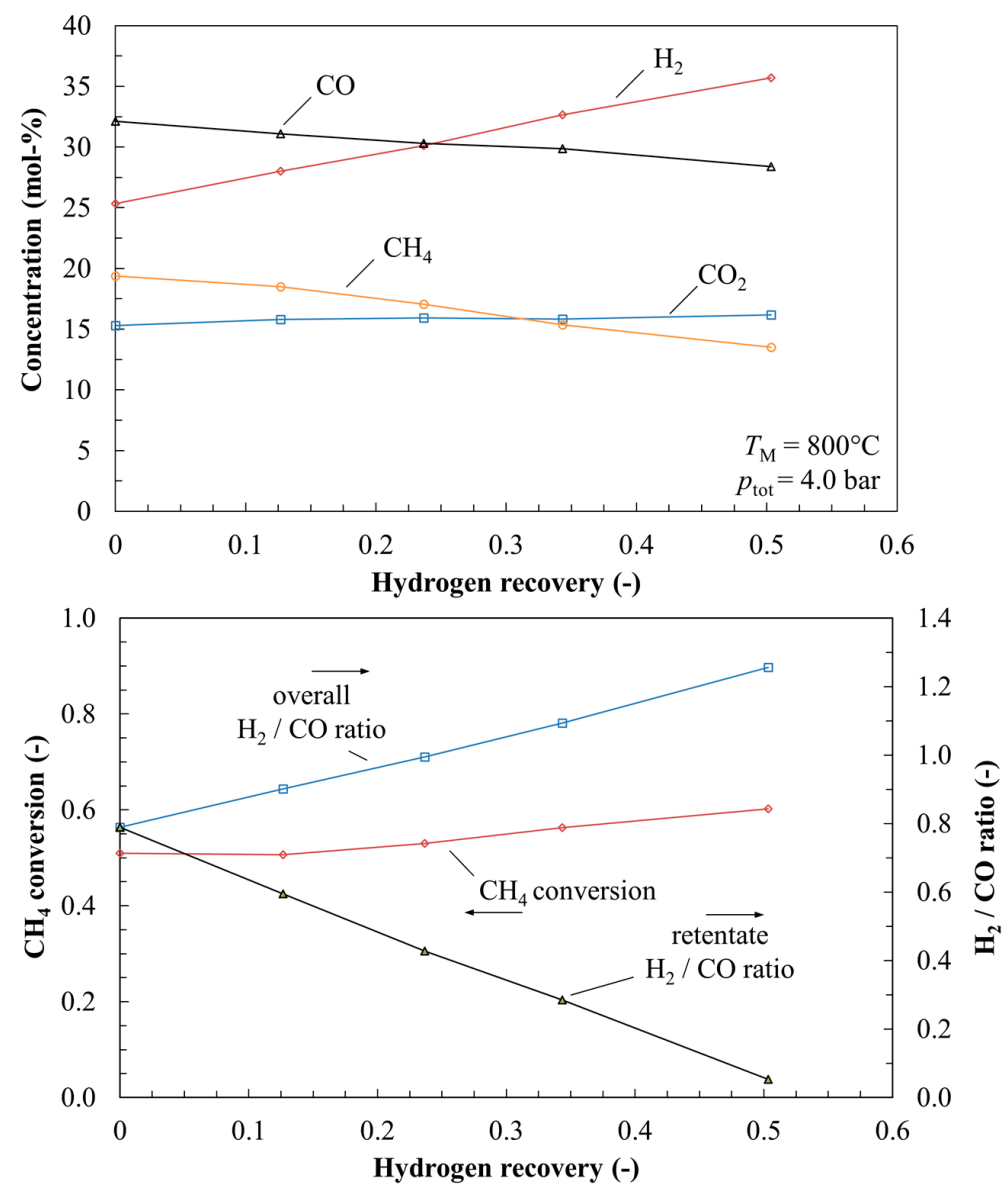

Figure 5. Influence of hydrogen separation on gas composition, $\mathrm{CH}_{4}$ conversion and $\mathrm{H}_{2} / \mathrm{CO}$ ratio at reference point: $150 \mathrm{~L} \mathrm{~min}^{-1} \mathrm{CO}_{2}, 150 \mathrm{~L} \mathrm{~min}^{-1} \mathrm{CH}_{4}$, membrane temperature: $800{ }^{\circ} \mathrm{C}$, system pressure 4.0 bar.

After the measures described in the preceding subsection, no more coke formation was observed. The carbon balance was calculated for the different membrane operation points and were closed by approximately $95 \%$; the difference to $100 \%$ can be explained by measurement uncertainties.

Figure 6 shows the results from the parameter study given in Table 1 on these parameters. Target values were the hydrogen recovery with the membranes as well as the methane conversion 
with and without hydrogen separation. As a comparison for the methane conversion, the equilibrium conversion was calculated with Aspen Plus NRTL model.
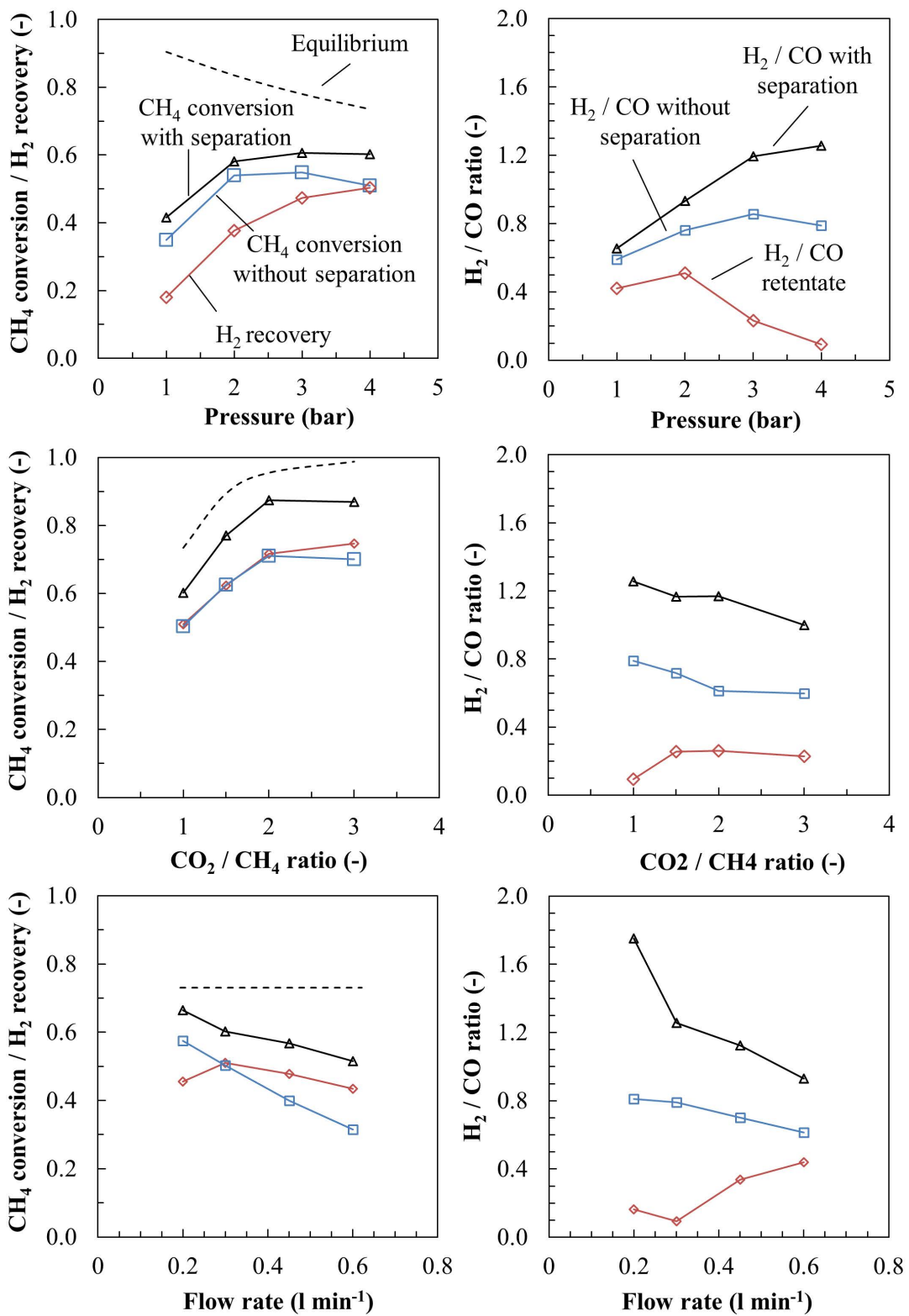

Figure 6. Parameter study for $\mathrm{CH}_{4}$ conversion, $\mathrm{H}_{2}$ recovery (left column) and $\mathrm{H}_{2} / \mathrm{CO}$ ratio (right column) for methane dry reforming at a process temperature of $800{ }^{\circ} \mathrm{C}$; Equilibrium conversion (dashed) calculated with Aspen plus NRTL model.

The system pressure has a high influence on the hydrogen recovery and thus the $\mathrm{CH}_{4}$ conversion. Methane conversion rises with the system pressure, which might be related to an increased residence time in the measurement cell due to the lower flow velocity. This shows that the system is not in equilibrium state. Higher methane conversion and system pressure lead to an increased hydrogen partial pressure favoring the membrane separation and leading to a higher hydrogen recovery. With an increased methane conversion due to pressure increase and hydrogen separation, the $\mathrm{H}_{2} / \mathrm{CO}$ ratio also rises significantly.

The $\mathrm{CO}_{2} / \mathrm{CH}_{4}$ ratio of the feed gas has a very high influence on $\mathrm{CH}_{4}$ conversion, although a complete conversion of the $\mathrm{CO}_{2}$ is only possible at $\mathrm{CO}_{2} / \mathrm{CH}_{4}$ ratios higher than 1 due to the 
stoichiometry of the reaction. This also leads to a dilution of the produced synthesis gas with $\mathrm{CO}_{2}$, which might pose problems in subsequent synthesis gas processing. The $\mathrm{H}_{2} / \mathrm{CO}$ ratio of the product gas however is declining only to a minor degree. The $\mathrm{H}_{2} / \mathrm{CO}$ ratio of the product gas can be adjusted by changing the specific membrane area or the trans-membrane pressure difference to fit each possible downstream synthesis process.

An increased flow rate leads to lower $\mathrm{CH}_{4}$ conversion, probably related to the decreased residence time. This also shows the dependency on reaction kinetics as observed in the pressure experiments. The $\mathrm{H}_{2} / \mathrm{CO}$ ratio lowers due to a limited conversion of methane at higher flow rates. Equilibrium conversion was not reached in the experiments; however, membrane separation had a major influence on the conversion.

These measurements illustrate the suitability of the nickel membranes for dry reforming: In contrast to other membranes, even high temperatures above $800{ }^{\circ} \mathrm{C}$ pose no problem to this membrane material. The catalytic properties of the nickel surface allow reasonable $\mathrm{CH}_{4}$ conversion, which could be further enhanced by a higher residence time. It is also possible to apply an additional catalyst to enhance $\mathrm{CH}_{4}$ conversion. Coke formation on the hot membrane surface was not observed during the parameter study. As outlined in the corresponding section, coke formation on the colder parts of the membrane could be avoided by the application of a nitrogen flush.

\subsection{Energy Balance}

The dimensioning of the membrane is an important parameter for a hydrogen generation process. A high conversion of the hydrogen-forming reactant can be achieved with a high membrane area. This results in a lower residual energy content of the retentate, which makes a utilization of this product stream more complicated. Hydrogen separation should therefore represent a tradeoff between a high hydrogen recovery and sufficient energy contents in the retentate. In this case, this stream could be used for heating the reforming process, which consumes a large amount of the enthalpy contained in the methane feed.

The energy content of retentate and permeate was determined in two campaigns with different $\mathrm{CO}_{2} / \mathrm{CH}_{4}$ feed ratios. Figure 7 shows the results. As a result from hydrogen separation, the specific energy content of the retentate is decreasing. A process layout is possible from these data: It is possible to calculate the methane consumption from on-site hydrogen requirements, which allows a dimensioning of the membrane area.

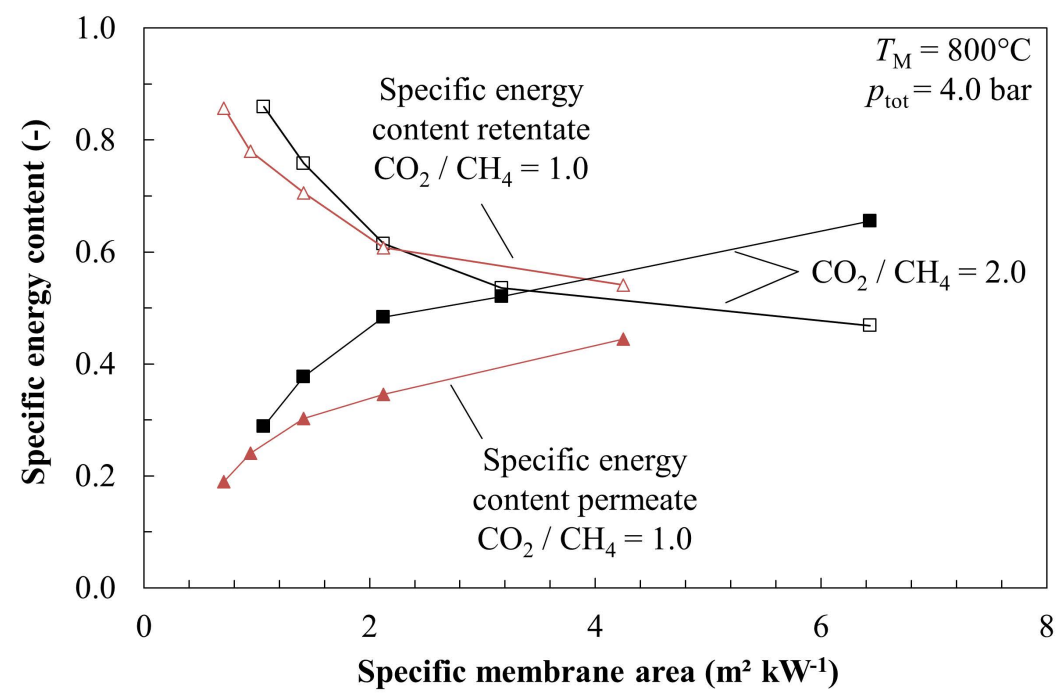

Figure 7. Specific energy content of permeate and retentate for membrane dry reforming at a process temperature of $800^{\circ} \mathrm{C}$. 
The energy content of the retentate can be used for further synthesis steps or process heating. As dry reforming is a highly endothermic process, a heating application of the low-caloric retentate seems reasonable. To give an impression on specific heating requirements, Figure 8 shows the specific energy content of the retentate, which may be used for combustion and the specific heat duty for the MDR reaction for different combustor efficiencies. The intersections of these lines give optimum operation points, where the remaining energy of the retentate is sufficient to operate the synthesis gas generation from MDR.

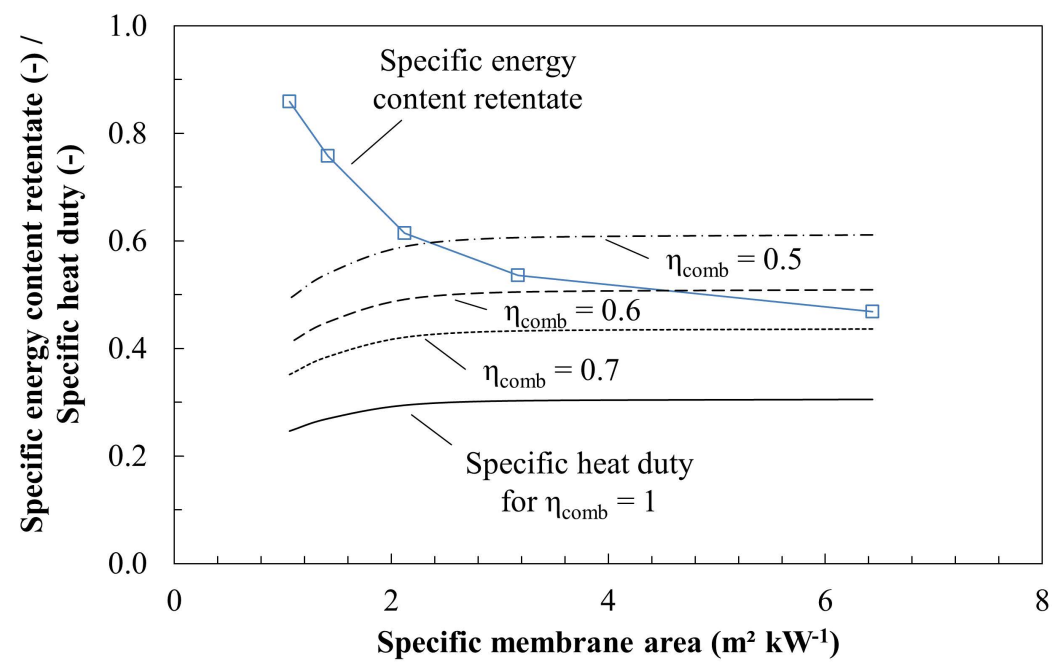

Figure 8. Comparison of specific energy content of retentate with specific heat duty for different combustor efficiencies.

\subsection{Comparison with Literature Results}

The usual approach for the methane dry reforming reaction is the application of palladium membrane reactors. These reactors suffer from limited process temperatures causing high carbon formation rates. Many of the recent publications concentrate on this topic $[6,16,17]$. The higher process temperature in the described experiments could significantly reduce coke formation.

In an early approach, Galuszka compared the performance of a packed bed reactor with a palladium membrane reactor and found an increase in methane conversion from $40.9 \%$ to $48.6 \%$ at $600{ }^{\circ} \mathrm{C}$. The $\mathrm{H}_{2} / \mathrm{CO}$ ratio was close to the ideal value of 1 .

Sumrunronnasak studied the dry reforming reaction in systems with and without catalyst [18]. He found a methane conversion at $800{ }^{\circ} \mathrm{C}$ without catalyst of $10-15 \%$, well below the results found in this publication. This hints at the catalytic activity of the nickel membranes. He also used palladium membranes at a temperature of $550{ }^{\circ} \mathrm{C}$ and achieved a significant increase in methane conversion to up to $70 \%$.

Paturzo et al. used a Ru-based membrane system at temperatures of up to $500{ }^{\circ} \mathrm{C}$. Methane conversion of $20 \%$ was achieved [6]. Bosko reported a methane conversion of $25 \%$ with a palladium membrane reactor and a high recovery of the produced hydrogen of $80 \%$ [7]. Gallucci et al. used conventional packed bed reactors as well as membrane reactors with porous and metallic dense membranes. Methane conversion could be raised by the application of the dense metal membranes from $17 \%$ to $27 \%$. Porous membranes had a negative effect on the conversion [1].

Overall, methane conversion with other membrane reactors did not show methane conversion as high as the published setup. This results from the increased reaction temperature, which is not possible with composite membranes. One drawback of this setup is the lower hydrogen flow through the membrane due to the high wall thickness. 


\section{Conclusions}

The paper shows measurements with a nickel membrane bundle for the generation of hydrogen from dry reforming and analyzes the impact of hydrogen separation on thermochemical equilibria. This leads to the following conclusions:

- The suitability of the nickel membranes for hydrogen separation and catalysis of the dry reforming reaction in the high temperature regime at $800{ }^{\circ} \mathrm{C}$ could be proven.

- Carbon formation was observed at colder parts of the membranes. Avoiding contact of the synthesis gas with catalytic surfaces at temperatures below $800{ }^{\circ} \mathrm{C}$ solves this problem.

- The membrane reactor achieved a methane conversion of up to $70 \%$ without using an additional catalyst. With a recovery of $50-70 \%$ of the hydrogen with the nickel membranes, the conversion could be enhanced to up to $85 \%$.

- Equilibrium conversion was not yet reached, probably due to the limited residence time in the measurement cell. It should be possible to further enhance conversion and hydrogen recovery by optimizing the reactor geometry or additional catalyst.

- The energy balance allows the application of the mentioned results for a technology transfer towards a possible commercialization of the concept.

Ongoing developments at the institute of energy process engineering (EVT) concentrate on the application of membranes to energy process engineering and synthesis gas conditioning for subsequent syntheses of second generation fuels. In this context, the MDR process provides an interesting conversion pathway for $\mathrm{CO}_{2}$ in a $\mathrm{CO}_{2}$-lean economy.

Acknowledgments: The authors thank Benjamin Heunisch for assistance with the experimental work carried out for this publication. This research is carried out in the framework of the Bavarian Hydrogen Center (BHC) joint research program. The authors would like to acknowledge the support provided by the Bavarian State Ministry of Science, Research and the Arts.

Author Contributions: Jonas Leimert conceived and designed the experiments; Jonas Leimert performed the experiments; Jonas Leimert, Jürgen Karl and Marius Dillig analyzed the data; and Jonas Leimert and Marius Dillig wrote the paper.

Conflicts of Interest: The authors declare no conflict of interest.

\section{Abbreviations}

The following abbreviations are used in this manuscript:

\begin{tabular}{lll}
\multicolumn{2}{l}{ Latin letters } & \\
$A$ & Surface area & $\mathrm{m}^{2}$ \\
$E$ & Specific energy content & - \\
$E_{A}$ & Activation energy & $\mathrm{kJ} \mathrm{mol}^{-1}$ \\
$\Delta H_{298}^{0}$ & Standard reaction enthalpy & $\mathrm{kJ} \mathrm{mol}^{-1}$ \\
$H D$ & Specific heat duty & - \\
$H_{u}$ & Lower heating value & $\mathrm{kJ} \mathrm{kg}^{-1}$ \\
$n$ & Partial pressure exponent & - \\
$\dot{n}$ & Molar flow rate & $\mathrm{mol} \mathrm{s}^{-1}$ \\
$P$ & Permeability & $\mathrm{mol} \mathrm{m}^{-1} \mathrm{~s}^{-1} \mathrm{~Pa}^{-0.5}$ \\
$p$ & Pressure & $\mathrm{Pa}^{-}$ \\
$R$ & Hydrogen recovery & - \\
$S_{f}$ & Separation factor & - \\
$X$ & Conversion & - \\
$Y$ & Yield & - \\
$\Delta x$ & Wall thickness & $\mathrm{m}$ \\
$\mathrm{Greek}$ letters & \\
$\eta$ & Efficiency &
\end{tabular}




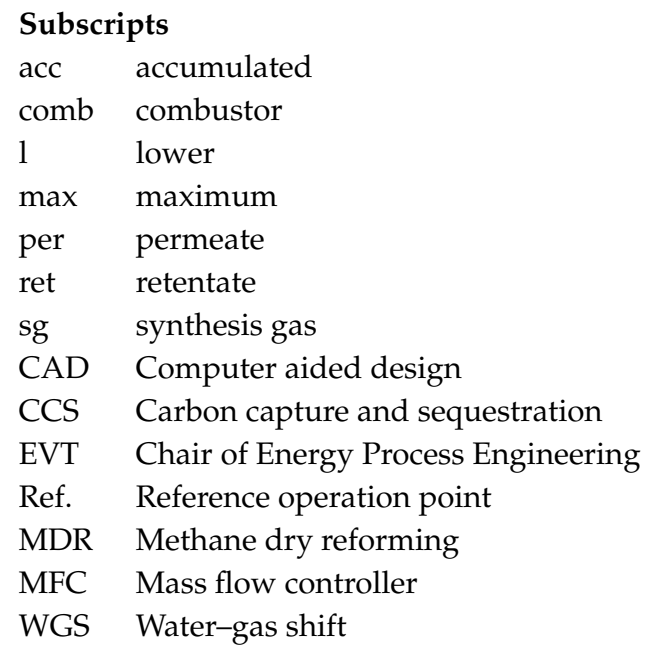

\section{References}

1. Gallucci, F.; Tosti, S.; Basile, A. Pd-Ag tubular membrane reactors for methane dry reforming: A reactive method for $\mathrm{CO}_{2}$ consumption and $\mathrm{H}_{2}$ production. J. Memb. Sci. 2008, 317, 96-105.

2. Usman, M.; Wan Daud, W.; Abbas, H.F. Dry reforming of methane: Influence of process parameters-A review. Renew. Sustain. Energy Rev. 2015, 45, 710-744.

3. Schulz, L.A.; Kahle, L.C.S.; Delgado, K.H.; Schunk, S.A.; Jentys, A.; Deutschmann, O.; Lercher, J.A. On the coke deposition in dry reforming of methane at elevated pressures. Appl. Catal. A Gen. 2015, 504, 599-607.

4. Schwab, E.; Milanov, A.; Schunk, S.A.; Behrens, A.; Schödel, N. Dry reforming and reverse water gas shift: Alternatives for syngas production? Chem. Ingenieur Technik 2015, 87, 347-353.

5. Oyama, S.T.; Hacarlioglu, P.; Gu, Y.; Lee, D. Dry reforming of methane has no future for hydrogen production: Comparison with steam reforming at high pressure in standard and membrane reactors. Int. J. Hydrogen Energy 2012, 37, 10444-10450.

6. Paturzo, L.; Gallucci, F.; Basile, A.; Vitulli, G.; Pertici, P. An Ru-based catalytic membrane reactor for dry reforming of methane - Its catalytic performance compared with tubular packed bed reactors. Catal. Today 2003, 82, 57-65.

7. Bosko, M.L.; Múnera, J.F.; Lombardo, E.A.; Cornaglia, L.M. Dry reforming of methane in membrane reactors using $\mathrm{Pd}$ and $\mathrm{Pd}-\mathrm{Ag}$ composite membranes on a NaA zeolite modified porous stainless steel support. J. Memb. Sci. 2010, 364, 17-26.

8. Julbe, A.; Farrusseng, D.; Guizard, C. Porous ceramic membranes for catalytic reactors-Overview and new ideas. J. Membr. Sci. 2001, 181, 3-20.

9. Pfefferle, W.C. Process for Producing Hydrogen. Patent US 3251652 A, 7 May 1966.

10. Gallucci, F.; Fernandez, E.; Corengia, P.; van Sint Annaland, M. Recent advances on membranes and membrane reactors for hydrogen production. Chem. Eng. Sci. 2013, 92, 40-66.

11. Quicker, P. Dehydrierung von Ethylbenzol zu Styrol. Ph.D. Thesis, FAU Erlangen, Nuremberg, Germany, 2000.

12. Schäfer, C.; Karl, J. Abschlussbericht ReGasNet, Teilprojekt 12: In-Situ Abtrennung von Reinst-Wasserstoff bei der Allothermen Wasserdampfvergasung; Technical Report; Technische Universität München, Lehrstuhl für Energiesysteme: München, Germany, 2007.

13. Leimert, J.M.; Karl, J. Nickel membranes for in-situ hydrogen separation in high-temperature fluidized bed gasification processes. Int. J. Hydrogen Energy 2016, 41, 9355-9366.

14. Melin, T.; Rautenbach, R. Membranverfahren-Grundlagen der Modul- und Anlagenauslegung, 3rd ed.; Springer: Berlin/Heidelberg, Germany, 2007; p. 584.

15. Basile, A.; Julianelli, A.; Longo, T.; Liguori, S.; De Falco, M. Pd-based Selective Membrane State-of-the-Art. In Membrane Reactors for Hydrogen Production Processes; De Falco, M.; Marrelli, L.; Iaquaniello, G., Eds.; Springer London, UK, 2011; pp. 20-56.

16. Galuszka, J.; Pandey, R.N.; Ahmed, S. Methane Conversion to Syngas in a Palladium Membrane Reactor. Catal. Today 1998, 46, 83-89. 
17. Lavoie, J.M. Review on dry reforming of methane, a potentially more environmentally-friendly approach to the increasing natural gas exploitation. Front. Chem. 2014, 2, 1-17.

18. Sumrunronnasak, S.; Tantayanon, S.; Kiatgamolchai, S.; Sukonket, T. Improved hydrogen production from dry reforming reaction using a catalytic packed-bed membrane reactor with Ni-based catalyst and dense PdAgCu alloy membrane. Int. J. Hydrogen Energy 2016, 41, 2621-2630.

(C) 2017 by the authors. Licensee MDPI, Basel, Switzerland. This article is an open access article distributed under the terms and conditions of the Creative Commons Attribution (CC BY) license (http:/ / creativecommons.org/licenses/by/4.0/). 